\title{
Critical Observation on Methodologies of Select Doctoral Research Studies
}

Dr Indrajit Goswami ${ }^{\dagger}$

\section{Abstract}

The present article aims to critically observe and interpret the methodological deficiencies as found in randomly selected 14 doctoral theses submitted to two different universities in India. Despite their serious deviation from the expected methodological standards, all those theses were accepted and approved by the universities and scholars concerned conferred with PhD degrees. Undoubtedly, those theses kept in the reference sections at the respective university libraries would potentially misguide and mislead the future researchers. Some of the common technical deficiencies, as have been noticed, include (1) absence of careful thoughts in framing research titles, (ii) biased method of data collection, (ii) absence of logical explanation in favour of sample size and sample selection process, (iii) designing and execution of instrument for data collection, (iv) theory formulation in terms of framing of objectives, hypotheses and operational definitions etc. The article attempts to present the critical observations on case-to-case basis so that their conceptual, instrumental and procedural deficiencies and deviations are easily understood by the academicians, researchers and students. The content of this article is divided in to three broad sections. The first section deals with an introduction to quantitative and qualitative research methods and their advantages and limitations. The next section deals with the review of the selected theses followed by conclusion and suggested remedial measures. The objective of this article is purely academic and its scope is limited to enhancement of quality of future research studies in the domains and related fields.

Key words: Doctoral study, Methodological deviations and deficiencies, Title of study, Researchers' biases

\footnotetext{
${ }^{\dagger}$ Director, Department of Management Studies, INFO Institute of Engineering, Sathy Road, Kovilpalayam, Coimbatore: 641107, Tamil Nadu, India, Email: idrgoswami@gmail.com

(C)2014 Goswami. This is an Open Access article distributed under the terms of the Creative Commons Attribution License (http://creativecommons.org/licenses/by/2.0), which permits unrestricted use, distribution, and reproduction in any medium, provided the original work is properly cited.
} 


\section{Introduction}

Apart from their contribution to theoretical development in respective subject domains, the contemporary research in business/management studies and agricultural extension programs are expected to contribute substantially to 'decision making' in the respective fields. In recent times, the teaching, training, mentoring and discourses in management and agricultural extension education have developed an obsession to 'research' with a perspective of their diagnostic and curative functions (Goswami, 2012). There is a growing trend to apply for different research grants and an enthusiasm to pursue doctoral studies among academicians, scholars and other professionals. Several autonomous institutions and universities have been encouraging interested scholars to pursue doctoral studies through part-time mode. Undoubtedly, such opportunities have paved the way to register for supervised research study, but evidences reveal that the expected standard of such researches has neither been protected nor promoted for ensuring their present as well as future relevance.

There are four main aspects of the research methodology: research design and strategy; method of sampling; development of instrument and data collection; and determining the application of statistics and data analysis. If methodology is neglected and compromised, the results of a study could be misleading. To some extent, we can afford the limitations of a research study but never its compliance to scientific principles and the very basic fundamental deficiencies in methodology. While limitations may enable the researcher to suggest improvements in further research, methodological errors demand a complete review of the conceptual framework of the study being undertaken and redesigning of the execution plan. Methodological errors and inadequacy not only mislead the results of a research project but weaken the basic purpose of research as an academic subject and mislead the entire community of future researchers/scholars. The present article deals with 14 doctoral theses, selected randomly from the reference sections of two leading universities in Tamil Nadu, India. The objective of the paper is purely academic and here an attempt has been made to critically observe the methodology of the selected theses to understand the deviations from expected standards, if any, in the research methodologies of the selected theses.

Before entering into the methodological analysis, it seems essential to understand the characteristics of quantitative and qualitative methods in social research. The following section presents a brief review of literature on both of the methods.

\section{The Quantitative Method}

According to Babbie (2010); Brians et al. (2011); McNabb (2008), and Singh (2007), quantitative methods emphasize on objective measurements and numerical analysis of data collected through polls, questionnaires or surveys. It requires larger sample size for drawing conclusions and for generalisation of findings on the target population across different groups and communities. Hence, it is essential to scientifically explain the sample plan, design of tools, the validity of data and statistical applications. There are certain ethical obligations of the researcher. It includes: Reporting of unanticipated events that occurred during data collection; Explaining how the actual analysis differs from the planned analysis; and, Making it transparent about handling of missing data (Black, 1999). In addition, the researchers need not to be obsessive to statistical analysis and applications. They have to choose just minimal statistical procedure, which would be adequate for achieving objectives and testing hypotheses. Since data in the form of numbers and statistics are one of the major characteristics of this method, so deviation from the standard norms of convergent reasoning may dilute the very basic purpose and advantages of qualitative method. 


\section{Limitations of Quantitative Methods}

- Quantitative data is efficient but may fail to address the contexts;

- The in-depth analysis is hardly possible due to its predominant empirical nature;

- Due to 'structural bias', many times the interpretation and discussion actually reflect the views of the researcher instead of the participating subject (Babbie, 2010);

- It is not effective for any micro-level analysis of social and behavioural problems; and

- It is unique in terms of its nature of replicability and repetitiveness; hence, it may encourage plagiarism among prospective scholars, who may be interested in pursuing MPhil or PhD studies.

\section{The Qualitative Method}

Qualitative research is often criticised as biased, small-scale, anecdotal, and/or lacking rigor. However, with this method, subjects can be examined in detail and in depth because it is flexible and does not contain any structural bias. It provides enormous scope to use researchers' professional wisdom and experience to plan, execute, understand, interpret and discuss the issues or problems at the individual or micro level. The reasoning and conclusion may not either require any quantitative measurement or calculating the statistical significance. If it is carried out properly, it can give us reliable, credible and rigorous insights and information. However, in qualitative research too, there needs to be a way of assessing the extent to which claims are supported by convincing evidence (Anderson, 2010). The validity of data is ensured by accurate and honest representation of the phenomena, whereas the reproducibility of the findings can establish the reliability of the study. Validity can be substantiated by a number of techniques including triangulation use of contradictory evidence, respondent validation and constant comparison (McNabb, 2008).

\section{Limitations of Qualitative Research}

- Research quality is heavily dependent on the researcher's skills and hence may not be free from researcher's personal biases;

- Issues of anonymity and confidentiality can present problems when presenting findings; and

- The process is often time consuming and findings cannot be generalised to a larger population.

\section{The Review Plan}

A total number of 14 doctoral theses, which awarded PhD to the respective scholars during 2002 to 2011, were randomly selected from two university libraries in Tamil Nadu. Those were studied thoroughly, especially the methodology part, by the author. Neither the scholars of those theses were contacted nor their research supervisors. Therefore, there was no primary source of data for writing this article. The data and descriptions as presented in those selected theses have been used in the present review. The names of the universities, research scholars, supervisors and places including districts and cities will not be mentioned in the article to protect their privacy. In addition, to ensure better confidentiality, the titles of the studies have been replaced with 'area of study'. The selected theses, hereafter referred as cases, have been divided under four broad categories, such as 'Market and Management Research', 'Market and Perception Research', 'Labour Market Research' and 'Miscellaneous'. The observations are presented as case-to-case basis and no attempt has been made either to compare the merits or demerits of the cases. 


\section{Market and Management Research}

\section{Case: 1}

Area of Study: Implications of Change Management Practices at a Multi-specialty Hospital

\section{Methodology}

It was a case study and it used exploratory research design. Total 96 doctors were selected purposively as samples. A formal, structured and standardized interview schedule was used for data collection. In the words of the scholars, "questions and their sequence were predetermined in advance". The interview schedule contained 163 items to be responded on different parameters such as five-point scale, nominal scales, ordinal scale, etc. As a part of 'limitations of the study', the scholar has mentioned that because of doctors' busy schedule, interview could not be conducted in length. In addition, many doctors expressed unwillingness during interview.

\section{Observation}

'Change management' is neither a new nor an unknown area of research. There is no dearth of literature in the domain. Just one attempt of search on 'Google' with key words 'change management theories' had shown 4,170,000 results (0.24 seconds) (checked on 29-1-14 at $07.45 \mathrm{pm}$ ). Theories, models, processes, etc. are available in plenty to understand and plan a study in the given subject. Hardly, there is any scarcity of earlier research studies and findings on the similar contexts. Hence, instead of identifying it as an 'exploratory' study, it could have been meaningful to accept it as a descriptive study. Further, a case study with an 'exploratory design' and a 'standardized', 'formal' and 'well-structured' interview schedule hardly would convince anyone. Rather a well-structured questionnaire or interview schedule could be used in a study, where the researcher would have clearly defined research objectives and questions similar to a quantitative or empirical research (Brians et al., 2011). Case studies in social science research, especially in behavioural science, are predominantly qualitative in nature. There interviews are not to be restricted to specific set of pre-decided or predetermined questions and/or measurement scales. In a case study, the contextual details are given more importance than testing hypotheses with quantitative data (Singh, 2007). However, the study under observation failed to provide substantial discussion on 'implications of change management' in the sampled institution. Apart from quantitative data and statistical analysis, there is hardly any in depth discussion on any particular issue or 'implications'.

The research mentioned that "total 96 doctors were selected purposively as samples". What was the purpose or rationale? Not yet explained in the method. In addition, the size of target population had not been mentioned anywhere in the thesis. Even after purposive selection of 96 respondents, the researcher reported some limitations in the form of inconveniences of the respondents. Neither the researcher could conduct interviews with all the 96 respondents, nor could she complete many of the interviews. The limitations she cited included (i) busy schedule of the doctors, and (ii) many expressed unwillingness to continue with the process of interviews. Firstly, the researcher could have avoided meeting all of them in hospital or could have taken prior consent for the purpose. Secondly, she could have avoided making so lengthy interview schedule with total 163 statements to be responded on different measurement scales, which included five-point scales, nominal scales, ordinal scales, etc. Hence, the limitations cited in the methodology chapter were not actually the limitations of executions of plan, but the drawback and weakness of the research plan itself.

\section{Case: 2}

\section{Area of Study: Customer Relationship Management and Retention}

\section{Methodology}


It was a comparative study with reference to motor insurance customers. The study used the descriptive research design and executed random sampling method to select 500 respondents. The scholar used systematic sampling method for selection of insurance products from ten stores. In addition, the scholar has mentioned that "the target samples were accessed through survey method and the survey was administered through personal interview method". As data collection tool, a structured questionnaire was used. The two research objectives read as "(i)...an in-depth analysis of customer satisfaction of motor insurance customers and try to identify the 'maintainers' and 'enhancers' of customer satisfaction, and (ii)... 'loyalty' among motor insurance customers".

\section{Observation}

The title of the study is not free from ambiguity. Customer retention is not something separate but an integral part of CRM strategy of any company. If CRM is effective, a positive impact will be better customer retention. Hence, retention can be an outcome of CRM. It is expected that the title of any research study, more so at the doctoral level, would be very clear, understandable and focused. Even if it is perceived that 'retention' has been accepted by the researcher as the outcome of CRM, the title does not establish that. Alternatively, it could be a comparison between 'CRM' and 'retention' status of customers at different motor insurance companies. However, from the methodology it has been understood that the scholar had not yet selected insurance companies to compare but he had selected insurance products from ten different stores. What he wanted to mean by 'stores', not yet defined. Further, there was no description on 'systematic selection method of insurance products'. Similarly, the selection process of respondents lacks objectivity. A combination of 'random sampling, survey method and personal interview' does not yet make any sense. In addition, it could not convince about how far an 'in-depth analyses' would be possible by a descriptive method and by using a 'structured questionnaire'. The terminologies like 'maintainers' and 'enhancers' are not yet defined and no further description has been mentioned about their measurement process.

\section{Case: 3}

\section{Area of Study: Consumer Behavior towards Selected Household Products}

\section{Methodology}

It is a descriptive study. The researcher used structured interview schedule and had taken a sample size of 500 consumers and 50 vendors. The interview schedule was 16 pages (standard A-4 size with 1.5 line spacing) long with 267 questions and statements framed to collect demographic data and problem specific data. It also included nominal scales, ordinal scales and Likert-type 5-point scales to measure consumers' satisfaction, attitude and several other attributes.

\section{Observation}

There had been no specific justification mentioned about how the size of sample came to be 550. The universe of the study was not defined and the locale of sample collection was not clearly specified. In addition, the researcher did not appoint or engage any field worker or interviewer to conduct interviews. It was done independently by the researcher. The methodology adopted could raise several questions such as (i) How far it would be justified to conduct interview with a comparatively larger sample size? (ii) Would it be feasible and technically acceptable to incorporate a large number of questions /statements in the schedule? (iii) How much time it would take to complete an interview process with a respondent? (iv) Whether respondents were comfortable to be with the interviewer until the end of each interview process? (v) Whether respondents answered to all the 267 questions/statement? (vi) Why vendors were included in the sample? There is hardly any explanation given in the methodology to satisfy the above questions. It had been indicative that the researcher was 
over ambitious and hence compromised with the technical guidelines of scientific research. It had been apparently revealed that the researcher might have 'structural biasness' and 'sample biasness'.

\section{Case: 4}

\section{Area of Study: Customer Relationship Management in Retailing}

\section{Methodology}

The study was conducted with the customers in FMCG segment and it was based on descriptive design. A total of 510 retailers and 1140 customers were selected from a district as sample size. "The entire district was covered by using random sampling technique for retailers' survey." "For customers, convenience sampling was used." The scholar formulated hypotheses after defining his statistical tools used in the study.

\section{Observation}

Similar to the last case, the research process adopted in the study contradicts to the scientific guidelines of research. The 'contents' page in the thesis organized the process in the following sequence: (i) introduction and design of the study, (ii) review of literature, (iii) conceptual framework of CRM and ... (vii) Bibliography and (viii) Appendix. There is no specific sampling plan mentioned in the report. Neither the scholar has mentioned about how many FMCG retailers are there in the district, nor did he define the population of customers. With these given circumstances, the selection of 510 retailers by random sampling technique, and selection of 1140 customers through convenient sampling do not make any sense. Either the number of sample or the process of their selection is hardly free from scholar's personal biases. In the given circumstances, the sample size might not be qualified as representative of entire population of retailers and customers in the district.
Case: 5

Area of Study: Emotional Intelligence, Adjustment, Decision Making and HR Perception of Marketing Executives in Engineering Industries in Coimbatore

\section{Methodology}

A combination of descriptive and diagnostic research designs was used. The sample size was 500. The researcher formulated 55 nullhypotheses for testing. A structured questionnaire was used for data collection. The tool was divided in to six sections, respectively on 'Personal Profile', 'Emotional Intelligence Measurement Scale' (Haggerty, et al, 1989), 'Self Adjustment Scale' (Sharma, 1972), 'Family Adjustment Scale' (Hatia and Chandha, 1998), Decision Making Scale' (Janis and Mann's, 1997) and questions on HR activity. There were 120 statements spread over six sections, which included questions on personal profile.

\section{Observation}

First, the methodology of the study does not clearly justify the rationale behind combination of two methods, i.e., descriptive and diagnostic. The diagnostic studies generally involve clinical insights and analyses and so it may be inadequate, if data are collected through questionnaires. More specifically the diagnostic observations may require a considerable degree of direct participation and intervention of the research investigator. Instead of a questionnaire, an interview schedule would have been a better option for conducting a diagnostic study. The review of methodology of the thesis reveals that it is nothing more than a descriptive study with an over ambitious plans of drawing some forced conclusions. It appears that the data actually reflects the view of the researcher instead of the respondents. There has been bias in deciding the sample size and sampling technique. There is hardly any mention about how the sample size has come out to be 500 . There is a universal acceptance that under normal circumstances the rate of return of duly filled-in questionnaires is not more than 35-40 percent. However, the methodology of the thesis does not mention 
about how many duly filled-in questionnaires have been returned and how many of them have been adequately filled to be considered for final analyses. The title of the study lacks focus and direction. The researcher has used many variables or attributes and has taken them for bivariate and multivariate analyses, but there is no operational definition given on each measurable variable in the report. The thesis does not provide any theoretical narration to show or describe any possible interdependence of the selected variables.

\section{Market and Perception Research}

\section{Case: 6}

\section{Area of Study: Brand and Product Features as Determinants of Purchase Intention}

\section{Methodology}

An empirical study with 500 samples collected through snowball sampling method. The researcher used a structured questionnaire and taken six months to complete processing of the data collected from the respondents. The following three objectives were included to address: a) the background characteristics of the households who have been using the durable products, namely, mixer grinder, television, refrigerator and washing machine; $b$ ) assessment of the influence of brand factors such as brand heuristics, brand loyalty, perceived quality, brand association and overall brand equity on buyer's intention to purchase branded durable goods; and c) the evaluation of the influence of product features on the purchase of the durable products such as mixer grinder, television, refrigerator and washing machine.

To achieve the above objectives the researcher formulated the following two types of hypotheses ( $\mathrm{H} 1 \mathrm{a}$ and $\mathrm{H} 1 \mathrm{~b}$ ) for each product selected for the study. They are:

H1a: The brand factors such as brand factors such as brand heuristics, brand knowledge, brand trust, brand loyalty, perceived quality, brand association and overall brand equity has a significant influence on the purchase of specific brand of product.
H1b: The product features have a significant influence on the purchase of various brands of a product.

\section{Observation}

The study might be of contemporary importance but found to be planned with biased choices. Objectivity is lacking in terms of framing of objectives and hypotheses. The study objectives and hypotheses are overloaded with ambitious expectations of the scholar. Selection of four different consumer durables and seven different 'brand factors' from each product category do not make any sense. The 'brand factors' (perceived as variables) are not defined adequately. Hence, it had been difficult to understand the scope of the study. The title does not have any focus and it is very much subjective. It has not been clear from the methodology about the selection of brand and products. It could be different products of a single company or similar products from different companies. The methodology could not transparently discuss or address the requirements.

\section{Case: 7}

\section{Area of Study: Customers' Perception towards Modern Shopping Centers}

\section{Methodology}

A sample size of 500 customers was selected through convenient sampling method. The scholar used interview schedule as tool and attempted to conduct interview, while they were on shopping spree. One of the objectives of the study reads, "to study customers' ideas, opinions and preference towards the various aspects of modern shopping centers". The interview schedule was too lengthy with more than 100 items or statements to respond. It also included a five-point scale for measurement of perception. Neither the validity nor reliability of the instrument was tested nor was that any already used and tested scale.

\section{Observation}

The nature and scope of the problem is not yet defined with specific research questions. The 
constructs such as 'perception', 'ideas', 'opinions' and 'preferences' are not synonymous words, hence they need to be defined with certain observable or measurable parameters. Similarly, the inclusions of words like 'modern shopping centers' in the title dilutes the focus of the study. The shopping centres may refer to anything like wholesale or retail markets, super market or hypermarkets, single brand or multi-brand stores, malls etc. At any doctoral-level study, it is expected that the title of the study would be very specific, purposive and one where the premise of study is to be made very clear and transparent. Even in the methodology part, nothing has been defined with objectivity. The shopping areas are generally busy areas where sellers and customers are engaged in selling and buying of different goods or products. The modern shopping malls are equipped with different amenities like restaurants, theatre, gaming zones, etc. Customers may visit such places for a specific need or varied purposes. It could be even difficult to approach them to talk on research. Hardly there is any logic to accept that the scholar has conducted a lengthy interview (peacefully and uninterruptedly) with 500 selected customers. When the sample is larger and scattered, we may administer 'questionnaire'. Alternatively, we may appoint required number of research assistants (as interviewers) to execute the plan. Why did the scholar follow convenient sampling? There is no explanation given in the method. The perception may differ across genders, age groups, income groups, etc. However, neither the objectives nor the hypotheses could make it clear, if scholar had any such plan to study and measure perceptual differences across groups.

\section{Case: 8}

Area of Study: Attributes, Choice of Business and Perception on Success of Women Entrepreneurs

\section{Methodology}

It is a descriptive study. The sample size was 630. A structured interview schedule was used for data collection from primary sources. The schedule had six sections, respectively on 'personal profile' (included 12 items to answer), 'business profile' (45 statements to answer), 'entrepreneurial attributes' (20 statements on three point scale), 'entrepreneurial success factors' (18 items to arrange in rank order), 'problems on women entrepreneur' (16 statements on five point scale) and 'satisfaction of women entrepreneurs' (09 statements on three point scale). The researcher included two open-ended questions at the end of the schedule. Total 96 null-hypotheses have been formulated for testing and to fulfil the study objectives.

\section{Observation}

The title seems to be very generic and ambiguous. It is not very much clear whether the study wants to measure perception of women entrepreneurs or perception of others on them. It does not clearly spell out about the category of entrepreneurs, i.e. whether they are first, second or third generation entrepreneurs. In addition, the title does not mention about the geographical coverage of the study. It lacks transparency when the researcher does not mention either the time required for each interview or total time required to complete all 630 interviews. The researcher's plan to conduct interview with a highly structured schedule does not find any justification in the given context of the study. All the measurement scales used in the schedule are framed by the researcher herself and their validity and reliability has not yet been checked. The sampling strategy is not well defined and it appears to be irrational when the researcher claims that respondents have been selected randomly. There has been no plan of stratification of the target population or any other type of categorization on the basis of their urban or rural domicile, or age group or level of education, etc. In addition, it is quite difficult to accept that all 630-interview sessions have been conducted flawlessly with a set of 122 questions at a stretch. There is doubt about how long the participant-respondent will maintain patience and honesty to respond to all 
120 -scale items. Moreover, it is not feasible to expect them to express freely and genuinely to two open-ended questions at the end of a so long interactive interview session. The researcher has used all common descriptive statistics, including association and correlation tests.

\section{Labour Market Research}

\section{Case: 9}

\section{Area of Study: Performance of District Cooperative Milk Producers Federation}

\section{Methodology}

The study used multistage stratified random sampling method. Only one district was selected out of all districts where Operation Flood Program-I was implemented. Out of 37 milk routes in the selected district, 30 were selected. Later selected 30 routes were divided into two blocks-one fertile block and one nonfertile block. Then 20 milk producers' cooperative societies were randomly selected from each block, i.e. total 40 cooperatives from two blocks. Further, 15 members were randomly selected from each selected cooperative. As a result, the sample size came out to be 600 (300 from fertile block and 300 from non-fertile block). All 600 respondents were interviewed personally by the researcher. It took around three months to complete the interview process.

\section{Observation}

Except sampling plan, nothing has been defined as a part of research method. As per the description recorded in the thesis, the cooperative societies are represented by small, marginal and big farmers. However, there is no mention about landless farmers turned milk producers. The selection of one district appears to be biased since rationale behind such selection has not yet been mentioned. Sample size does not adequately represent the population of milk producers in the district. Since the study was on performance of the 'federation' of cooperatives, it would have been better to start the process of sampling at the level of federation, not district. Further, the study and methodology fails to throw light on measurement of performance and related variations among small, marginal and big farmers. All the selections in round figures, such as 30, 20, 15, 300 and 600, appear to be intentional and purposive to make calculations easier and comfortable. Either, the selection of 30 milk routes from existing 37 or randomly selection of 20 cooperative societies is not adequately justified by any reason, logic or rationale. In addition, it has been noted that the 'cost of milk production' at the farmers' level has been ignored towards measurement of performance of federation.

\section{Case: 10}

Area of Study: Work-family Conflict among Merchandisers of Knitting Industries in a Selected District

\section{Methodology}

It is a descriptive study which used convenient sampling method to select 605 participantrespondents. A structured questionnaire was used for data collection. The tool was divided in to two parts. The first part had 14 questions to probe on demographic background of the respondents. The second part was a four-point measurement scale with 99 statements, distributed in to 13 sub-sections.

\section{Observation}

Every convenient sampling method may involve some biasness. However to make it a true nonprobability method of selection and to make it more transparent and acceptable, we need to explain and justify the reason behind adopting convenient sampling method. Unless it is supported by a sound rationale, it remains potential for open criticism. The scholar in the study could not clearly narrate the justification of using convenient sampling. The variables taken for measurement and for tests of association and correlation were not clearly identified and defined. There is no mention about validity and reliability of the scale used. 
Case: 11

Area of Study: Problems and Prospects of Khalasi Labourers with Special Reference to a District

\section{Methodology}

This part included only the sampling plan and sample size. No further description of research strategy, i.e. methodology in true sense, has been given. "Samples of 1000 labourers were selected from the district, based on the convenience of the researcher, by adopting convenience sampling method." A structured interview schedule was used for data collection from selected samples. "The samples included unorganized labourers and migrant labourers." The researcher used separate interview schedules for each category.

\section{Observation}

There is no justification about how the sample size came to be 1000 . In addition, it lacks feasibility to accept that all 1000 respondents were interviewed by the researcher within the stipulated time period of around three months. It is nowhere mentioned about the target population. Hence, the sample size lacks credibility of being representative of a population. No operational definitions are given on 'unorganized labour', 'migrated labour' and 'khalasi labour'. The review of literature part is inadequate and does not clearly describe the research terms, their similarities and differences. The entire process of research here starts from confusions, since there is no theoretical explanation given on 'problems' and 'prospects'. It has been revealed from the analysis that it was basically a study of satisfaction of those labourers in their respective fields of labour. Hence, instead of putting the word 'problems' in the title, it could have been better to cite the specific research problem. The researcher mentioned that inadequacy of time was one of the limitations of her study. Time is indeed a scarce resource; however, an appropriate research plan can help us to estimate the required time. For example, time series designs may not consider time as constraint. It is imperative that 'cost-benefit analyses' is an inseparable part of decision making in research. Hence, the researcher must identify suitable alternative course of action as a part of research strategy.

\section{Case: 12}

\section{Area of study: Satisfaction, Prospects and Problems of Women Bidi Workers with Special Reference to Two Districts in Tamil Nadu}

\section{Methodology}

It has been revealed from the report that it was a descriptive study, but there was no mention about the research method in the thesis. "Out of four bidi-making districts two were selected because more number of women workers was there. The scholar used convenient sampling technique and selected 250 respondents from each district. An interview schedule was prepared and "circulated among HR Managers for verification". Interview was conducted with all 500 samples in a period of three months.

\section{Observation}

The research process adopted in the study contradicts to the scientific guidelines for social science research. The 'contents' page in the thesis organized the contents and process in the following sequence: (i) introduction and design of the study, (ii) review of literature, (iii) overview: Bidi industry, (iv) living and working conditions of bidi workers, ( $v$ ) analysis and interpretation, (vi) findings, suggestions and conclusions, (vii) bibliography and (viii) annexure. Generally, the methodology is to be finally decided after working on introduction, literature review and formulation of objectives (and hypotheses, if required). The scholar claimed that the sample size was not adequate but she did not mention the (appropriate or approximate) population of women bidi workers, either in Tamil Nadu or in two selected districts. The bidi-manufacturing process is not as organized as other manufacturing industries. Still it is considered as an unorganized sector and hardly there is any HR Manager in those manufacturing units. 
Case: 13

Area of Study: Quality of Work Life and Psychological Wellbeing among the Female Employees of Indian Private Banks

\section{Methodology}

It was a descriptive research study. The objectives were (i) to study personal profile of the respondents, (ii) to study their quality of work life, (iii) to study their psychological wellbeing, and (iv) to find out the relationship between QWL and psychological wellbeing. Only 19 banks ( 7 new and 12 old generation banks) were selected from a district of Tamil Nadu. 'Technology profile' of the banks was the determinant to distinguish between 'new' and 'old' banks.

The scale framed by NIOSH (National Institute of Occupational Safety and Health, USA, 2002) was used to measure QWL of women bank employees in Indian settings. The NIOSH's instrument includes total 72 items (or statements) but the researcher had taken it partially. Only 35 items were found suitable to Indian situations, so she used those 35 items on a 4-point scale. For measurement of 'psychological wellbeing', she used the scale developed by Carl Ryff. It had total 84 items distributed equally in 06 dimensions. The validity of this scale was checked with the help of HR managers and other bank officials. The researcher received 360 duly filled-in questionnaires out of total 560 distributed among respondents. Only 300 filled-in questionnaires were found complete and thus used for analysis.

\section{Observation}

First, all the rural-urban bias of sampled institutions was not addressed. While most of the old banks were located across the district, the new generation banks were situated in and around cities. The locale of study has not yet been mentioned in the method. The target population, i.e. women bank employees, is not defined. The pretest was conducted among 30 respondents, but there was no mention about whether those 30 respondents were included in the final sample or not. For achieving four research objectives, the scholar had formulated seven null hypotheses and for the purpose, she had taken many researchable variables. For data analyses and testing of hypotheses, she used ANOVA, factor analysis, Karl Pearson's Coefficient Correlation, Regression analysis, ttest, discriminant analysis and chi-square. It has been revealed that many variables were common to both QWL and 'psychological wellbeing' but were not defined separately according to their scope in the respective measurement tools. The scale developed by $\mathrm{NIOSH}$ was arbitrarily used by the scholar without any justification. How far the bank officials and HR managers could check the validity of another scale? Were they adequately qualified for that? No explanation to these questions has been given in the methodology chapter. As limitations of the research, the scholar mentioned that (i) "the respondents were hesitant to fill the questionnaires", (ii) "officials of private banks were reluctant to permit the scholar to collect data" and (iii) "respondents were busy during the banking hours, hence the scholar had to meet them outside". In the given context of the study, the first two limitations are irrelevant and the third one appears to be an inconvenience of the researcher, yet not the limitation of the study.

\section{Miscellaneous}

Case: 14

\section{Area of Study: Developing a Strategy for Tribal Development}

\section{Methodology}

The main objective was to do gap analysis between development of tribes habituating in Andaman and Nicober Islands and their civilian counterparts. Three categories of respondents were included in the study, viz. (i) primitive tribes, (ii) scheduled tribes and (iii) tribal development officials. The researcher purposively selected 55 (out of total 154 in Tirur) Jarwas and 14 (out of total 38 in Dugong Creek) Onges as primitive tribes and 111 Nicobarese (out of total 312 from Sawai, one of the 16 villages) as scheduled tribes. For the 
third component of samples, the researcher used census method and selected all 30 officials available at the field level. As rationale behind sampling process, the researcher mentioned that "keeping in view the time available, a sample of ' 180 tribes' was fixed for the conduct of study". A common 'interview schedule' was designed and used for collecting data from tribes as well as from the officials. For conducting interviews with the tribes, the scholar engaged community leaders as interpreters, who used to know 'spoken Hindi language'. The schedule was divided in to three parts. The first part included questions for gathering demographic information. The second part included 26 statements on different three- and five-point scales for measurement of attitude, involvement in community activities, for testing of their 'cosmopoliteness' and 'localiteness', etc. In addition, it had 15 open-ended questions to probe in to their level of aspiration, social participation and intra-tribal communication etc. The third part of the schedule was designed with different scales to measure awareness of tribes on their developmental schemes, perception of usefulness of tribal development programmes, content and strategies of selected tribal development schemes, assessment of participation of tribes, reasons for effective participation and constraints in participation. In addition to 111 statements on different scales, the part three of schedule included 65 open-ended questions to be answered by the respondents.

\section{Observation}

First, the title reads like a book, not an empirical research. It would be difficult to understand the research focus from the title. Next to that, an elabourate list of objectives in the thesis appears to be very much confusing and diluted. The blue print of research, i.e. the methodology is not yet planned adequately. Neither the scholar defined the methodology used in the study nor did she mention about it anywhere in the report. In places, she has repeatedly cited that "the study was primarily anthropological in nature. So she relied more on 'observation' and 'participation' technique". However, there is no specific mention about any observation or participation technique used, except a too lengthy and interactive process of interview. Even it lacks feasibility, when the scholar claims that she has administered successfully such a lengthy interview schedule with the Jarwas, Onges and Nicobarese and got all required data/information with the help of their respective community leaders. The sample selection process is not at all scientific. While the Jarawas and Onges were selected purposively, the selection of Nicobarese was done randomly from one of the 16 villages. The population, as mentioned in the method, includes different age groups including children. However, the selected respondents include only elder male and female, who were in the age groups of 18 years and above, including aged. No 'excluding' and 'including' criteria have yet been defined to make the sample adequately representative and valid. In addition, it is apparent that such a lengthy interview with overloaded questions and scale items would hardly be conducted flawlessly with the selected primitive tribes.

\section{Conclusion}

From the given premises, it is well understood that quality of doctoral studies is being compromised beyond justifications. The scholars and their supervisors are proportionately responsible for such scenario. There is a trend of pursuing quantitative researches, more so descriptive studies, among the scholars of the institutions selected for the study. In most of the cases, the process of research started from personal biases of the researchers in terms of their convenience of a particular 'sample size' and 'sampling technique'. It would not be an exaggerated statement, if it concluded that most of the theses are 'junks' and do not have any substantial contribution to the respective domain of knowledge. Invariably all the scholars do not have adequate knowledge about 'research methodology' and scientific temperament to pursue studies at doctoral 
level. It has been apparent that they are 'overambitious' with 'over-expectations' from their ill-conceived and technically paralyzed research studies. In most of the cases, the adopted 'tools', either questionnaire or interview schedule, are unexpectedly too lengthy to execute in real life situations. The review could satisfy that criteria. In most of the cases, the sampling process started abruptly without any adequate definition of target population for research. Such an endeavour is seriously harmful for the entire research community and misleading for the future scholars, when such theses are kept on racks of reference libraries at different universities and higher learning institutes. Are there any remedial measures to improve the situation? Obviously there could be some feasible and alternative solutions, provided 'the scholars/researchers' are granted the voice to raise their concerns and resentments. In addition, it requires interventions at macro and micro levels. At the macro level, we need to revisit the related policy guidelines where $\mathrm{PhD}$ has been declared as the mandatory qualification for pursuing career in academics. The appropriate authorities, such the education ministries, UGC and AICTE must consider prescribing a minimum requirement of 3-4 years of working experience for a candidate to qualify for a doctoral program. There must be some expert committee or board outside the jurisdiction of a university to decide the eligibility of a candidate to pursue doctoral studies. Such committee or board may have representation from the respective universities and registered supervisors of the applicant. At the micro level, each study must be guided by at least two supervisors, where one must be an expert in the subject domain and the other one desirably to be an expert or proficient in 'research methodology' and 'research statistics'. In no case, universities should allow the supervisors alone to submit the panel of experts for thesis evaluation. Rather, it must be the sole discretion of the university to set the panel, where the supervisors may be consulted and asked to suggest few experts to the panel. logic, justifications and rationale are grossly absent in the methodology of the selected theses. It is needless to mention that a strong theoretical foundation is essential to design an execution and measurement plan for an empirical study. None of the studies under

Similarly, for conducting the viva voce examination the same rule is to be followed.

\section{References}

Anderson, C. (2010). Presenting and Evaluating Qualitative Research. American Journal of Pharmaceutical Education, 74(8), p.141.

Babbie, E. R.. (2010). The Practice of Social Research. 12E. Belmont, CA: Wadsworth, Cengage Publications.

Black, T.R. (1999). Doing Quantitative Research in the Social Sciences: An Integrated Approach to Research Design, Measurement and Statistics. London: Sage.

Brians, C., Leonard,et al. (2011). Empirical Political Analysis: Quantitative and Qualitative Research Methods. 8E. Boston, MA: Longman.

Gay, L.R. and Peter, A. (2003). Educational Research: Competencies for Analysis and Applications. 7E. Upper Saddle River, NJ: Merril Prentice Hall.

Goswami, I. (2012). Collabourative Research in Management Education and its Inseparable Bond with Social Sciences. EXCEL International Journal of Multidisciplinary Management Studies, Vol: 2 (11), pp.231-239.

Hopkins, W.G. (2000). Quantitative Research Design. Sportscience, Vol: 4(1).

McNabb, D.E. (2008). Research Methods in Public Administration and Nonprofit Management: Quantitative and Qualitative Approaches. 2E. Armonk, NY: M.E. Sharpe.

Singh, K. (2007). Quantitative Social Research Methods. Los Angeles, CA: SAGE.

\section{About the Author}

Indrajit Goswami holds a Master's degree in Social Work from Visva Bharati University, Sriniketan, West Bengal, India. Later he 
obtained his Post Graduate Diplomas in HRM and Industrial Psychology, respectively from Indian Institute of Social Welfare and Business Management, Kolkata and NIIRD, Chennai. He obtained his PhD in professional ethics in 2007 from JRN Rajasthan Vidyapeeth University, Udaipur, Rajasthan.

He worked across different fields and target groups, including HIV/AIDS, Drug and Alcohol Abuse, Child Labour and other marginalized sections of society. He served different types of organizations such as NGOs, Development Authorities, Universities and B-Schools. His areas of expertise include human resource development, behavioural science, professional and corporate ethics, CSR, Non Profit Project Planning and Management etc. $\mathrm{He}$ has presented papers in national and international conferences and published papers in journals of national and international repute. Some of his recent works have been published in Taylor and Francis's 'Practice: Social Work in Action (April, 2012); Cengage Learning (2013); Concept Publishing (2014) etc. He is a blessed disciple of Yogacharya Sri Swami Sadhanananda Giri. 